\title{
The importance of model structural complexity when simulating aquatic food webs
}

\author{
$\underline{\text { Y. Li }}{ }^{\text {a,b }}$ and M.R. Hipsey ${ }^{b}$ \\ ${ }^{a}$ School of Environmental Science \& Engineering,The Ocean University of China, Qingdao 266100, China. \\ Email: liy15@student.uwa.edu.au \\ ${ }^{b}$ School of Earth and Environment, The University of Western Australia, Crawley WA 6009, Australia.
}

\begin{abstract}
The problem of simulating microbial interactions in aquatic systems is receiving considerable attention and has resulted in recent advances to ecological models for understanding and forecasting algal blooms. However, these ecological models often simplify microbial diversity and do not always provide an accurate picture of the nutrient flux pathways that occur in food webs due to the complicated nature of microbial interactions. This study used the FABM (Framework for Aquatic Ecosystem Models) framework to develop three ecological models of different structural complexity, that sequentially build on the classic 'Nutrient-Phytoplankton-Zooplankton-Detritus' (NPZD) model, to better understand the significance of specific microbial interactions ecosystem dynamics, namely the 'microbial loop' and 'viral shunt' (Figure 1).

The results of a 'Nutrient-Phytoplankton-Zooplankton-Detritus+Viruses' (NPZD+V) model were used to compare the influence of zooplankton mediated mortality relative to virus mediated mortality of phytoplankton. The results showed that virus mediated mortality via infection and lysis of phytoplankton can be as important as zooplankton mediated mortality via grazing under typical conditions. Next the results of the 'Nutrient-Phytoplankton-Zooplankton-Detritus+Viruses+Bacteria' (NPZD+VB) model indicated that the viral shunt can short circuit the microbial loop via viral infection and lysis of phytoplankton and bacteria, and thereby increase the transfer of material to the detrital pool. Furthermore, the more complex model structure that include the viral shunt and microbial loop pathways illustrated the importance of 'bottom-up' (resource) control of algal production via microbial interactions in aquatic ecosystems. These results help provide an improved mechanistic understanding for viral-bacterial-phytoplankton-zooplankton interactions in aquatic ecosystems and can help to guide decisions about appropriate model conceptualisations that can be used. Further work on systems analysis of the model structures is required to better understand their resilience and stable states that are likely to form under a range of nutrient enrichment conditions.
\end{abstract}

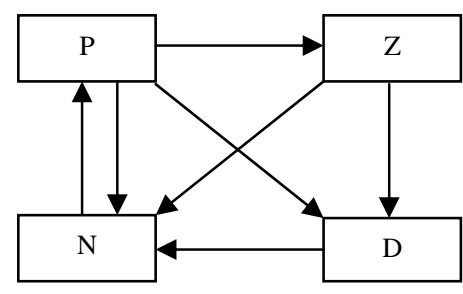

(a)

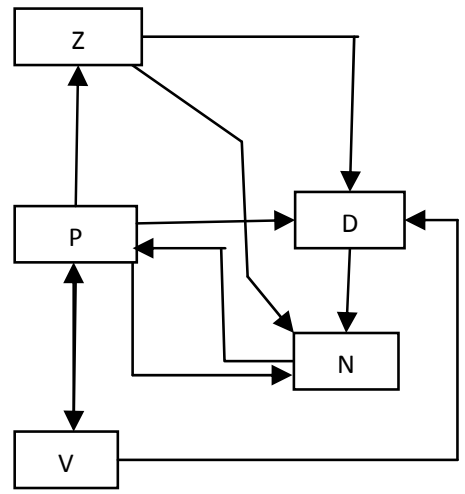

(b)

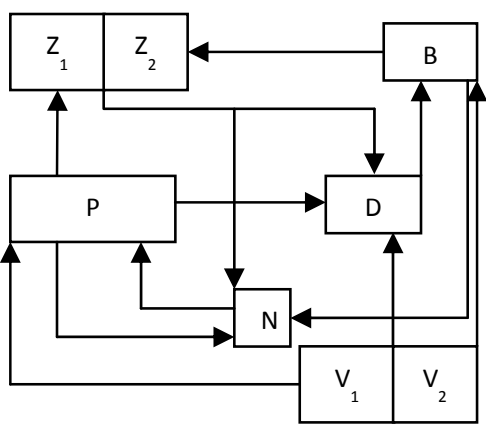

(c)

Figure 1 Structure of a) NPZD, b) NPZD+V, and c) NPZD+VB models (Note that $\mathrm{Z}_{1}$ refers to normal zooplankton; $\mathrm{Z}_{2}$ refers to the microzooplankton; $\mathrm{V}_{1}$ refers to the phytoplankton viruses; $\mathrm{V}_{2}$ refers to the bacteria viruses).

Keywords: aquatic ecosystem; viral shunt; algal blooms; microbial loop; ecological modelling 


\section{INTRODUCTION}

One of the most important aims of managing eutrophication in water bodies is the control of algal blooms (Anderson et al., 2002; Lewis et al., 2004). Modelling nutrients and microbial interactions in aquatic ecosystems has proven to be a useful tool for understanding the eutrophication processes that lead to algal blooms by describing the nutrient flux pathways in the food web (Guven et al., 2006; Li et al., 2013). Whilst the models are increasingly becoming more complex, present models are based on the early ideas embodied in modified prey-predator models (also known as Lotka-Volterra equations): the classic 'NutrientPhytoplankton-Zooplankton' (NPZ) models and 'Nutrient-Phytoplankton-Zooplankton-Detritus' (NPZD) models (Heinle and Slawig, 2013). These models have been successfully developed and applied widely for aquatic ecosystem research (eg. Popova et al., 2000; Edwards, 2001; Franks, 2002; Keller and Hood, 2011), with modern interpretations of this model structure being extended to simulate multiple plankton function groups (PFT's). However, these models assume a relatively simple flow of nutrients between autotrophic and heterotropic pools (Edwards et al., 2001), and do not always completely capture the complexity of microbial food web interactions. In many cases decisions about model structure are largely ad hoc.

The aim of this study is to better understand the manner in which nutrients move among microbial food webs, by considering two types of microbial interactions: the 'microbial loop' and the 'viral shunt' (Suttle, 2005; Hambright et al., 2007) relative to the classic NPZD models. Firstly, the microbial loop refers to the dynamics of the heterotrophic bacteria and microzooplankton grazers, and is also described as the detritalbased food web (Moore et al., 2004). Secondly, the role of viruses (V) in biogeochemical cycles has been well documented in aquatic ecosystems, with empirical results often challenging the traditional views of aquatic food webs (Wommack and Colwell, 2000). Nutrients released by viral lysis are usually organically bound, and subsequently affects nutrient availability and the flux pathways associated with $\mathrm{C}, \mathrm{N}$ and $\mathrm{P}$ cycling (Gobler et al., 1997). In particular, viruses catalyse the movement of nutrients from phytoplankton to detritus thus short-circuiting nutrient flow to higher trophic levels, termed the 'viral shunt' (Suttle, 2005). It has been estimated that $25 \%$ of the primary production in the ocean ultimately flows through the viral shunt (Wilhelm and Suttle, 1999), yet rarely is it considered when assumptions about model structure are made. It is therefore crucial to accurately quantify the role of the microbial interactions, and incorporate them into biogeochemical models.

From the point of view of primary producers in aquatic systems, the microbial loop and the viral shunt are 'bottom-up' (resource) controlling processes, whereas traditional models are based more on a 'top-down' (consumer) control of algal blooms. Whilst we acknowledge that often these more detailed process descriptions are intentionally lumped within the parameters of simpler models, this essentially implies that microbial interactions are being parameterized using empirical relationships; however, these empirical parameters are unlikely to be universal or are become site-specific. Improved modelling frameworks with a more realistic mechanistic basis for studying microbial interactions in aquatic ecosystems are therefore required (Mooij et al., 2010) in order for us to develop a more general understanding of how different microbial interactions influence food webs and nutrient pathways.

In this study, some exploratory work is reported that aims to understand the significance of how our model conceptualisations impact on water quality predictions. The analysis compares the classic 'NutrientsPhytoplankton-Zooplankton-Detritus' (NPZD) model with a) a model extended to include the viral shunt $(\mathrm{NPZD}+\mathrm{V})$ and b) a model extended to include the viral shunt and microbial loop (NPZD+VB) which was used to further assess the impact of viral shunt short circuiting of the microbial loop through nutrient cycling processes. By running the simulations with typical parameter values, we compared the simulated results of several biological variables and their ecosystem relationships to highlight the significance of microbial interactions in changing food web structure in aquatic ecosystems. Implications for the impact of model structure and resilience and stability of food webs to changing boundary conditions are briefly discussed.

\section{METHOD}

\subsection{Model structures}

Relative to the NPZD model, an NPZD+V model was made to include virus dynamics as an additional pressure on algal production in addition to the zooplankton compartments. A second, more complex NPZD+VB model, was also tested which combined viruses, bacteria, and zooplankton to investigate the impact of the viral shunt short circuit the microbial loop. It additionally considers two groups of viruses (prokaryotic and eukaryotic) and two groups of zooplankton (micro- and macro-grazers) and is most likely 
the closest to reality for most aquatic systems. Their model structures are described in Figure 1, which highlights the flows of resources in the model ( $\mathrm{N}$ is assumed in these simulations).

\subsection{Model parameterisation}

The equations of these ecological models (NPZD model, NPZD+V model, and NPZD+VB model) are compared in Table 1 to show the similarities and the differences between the models. Nutrient uptake by phytoplankton was modelled based on Michaelis-Menten kinetics, which was also limited by light availability. Most other processes were based on linear first-order kinetics. Refer to Li (2013) for details on individual parameterisations.

\subsection{Model setup}

The Framework for Aquatic Biogeochemical Models (FABM) is a recently developed community modelling framework for simulating the biogeochemical and ecological dynamics of aquatic ecosystems (fabm.sourcefore.net). FABM supports coupling of a diverse array of water quality and ecological models to various physical 'driver' models. Here a simple 0D model was employed. The seasonality was captured using available field temperature and light data obtained from Lake Kinneret (Israel) from 1997-01-01 to 1997-1231. All simulations were carried out with a time step of $12 \mathrm{~h}$. The model employs several ODE solvers, and the most simple Euler's method was employed here.

\subsection{Analysis approach}

To determine the difference of the viral shunt and the microbial loop on the key biological variables (viruses, bacteria, phytoplankton, zooplankton) and the nutrient pools (nutrient, detritus), each variable was compared under the different model structures. To determine the influence of model structure on key nutrient pathways the nutrient fluxes were averaged over the simulation period of one year.

\section{RESULTS}

\subsection{Model comparison}

It is clear that there were obvious differences in trends and magnitudes of some variables between different model structures (Figure 2). For example, the peak of phytoplankton growth in the NPZD model was higher than the peak in the NPZD+V model and the NPZD+VB model (Figure 2a), which was relevant to the impact of the viral shunt on primary production. Phytoplankton in NPZD+V and NPZD+VB models is $\sim 50 \%$ less than that in NPZD model. Also zooplankton is much higher in NPZD than in the more complex models indicating the lower food availability is impacting their net growth and potential to accumulate biomass. For the simulated viruses, another small peak of the NPZD+VB model occurred, which was relevant to the impact of the viral shunt on the microbial loop (Figure 2e and Figure 2f). Viruses also transfer nutrients from bacteria to detritus.

\subsection{Nutrient fluxes}

The difference between viral infection and zooplankton grazing illustrates that the phytoplankton mortality caused by viral infection and lysis is as important as the phytoplankton mortality caused by zooplankton grazing (Table 2). From the perspective of nutrient recycling processes, in the NPZD model, mineralization recycled $80 \%$ of total nutrient taken up by phytoplankton, and zooplankton excretion returned $17 \%$. In the NPZD+V model, because of viral infection, a large amount of nutrients were stored in the virus pool so that the viral infection was almost $0 \%$. However, the phytoplankton mortality was $11 \%$ (Table 2), which was much higher than zooplankton grazing $(0.3 \%)$ because the phytoplankton biomass was converted into viral biomass. In the NPZD+VB model, although the viruses mainly infected phytoplankton (87\%), viruses also infected bacteria (55\%), which increased bacterial uptake of nutrient (193\%) and bacterial excretion (135\%). This illustrated that the viral shunt can short circuit the microbial loop via increasing the 'bottom-up' control of bacterial mineralization but decreasing the influence of the 'top-down' control via zooplankton grazing. 
Table 1. Comparison of the NPVD model, the NPZD+V model, the NPZD+B model, and the NPZD+VB model.

\begin{tabular}{|c|c|c|c|}
\hline & NPZD & NPZD+V & NPZD+VB \\
\hline $\mathbf{P}$ & $\frac{d P}{d t}=d_{n p}-d_{p n}-d_{p d}-d_{p z}$ & $\frac{d P}{d t}=d_{n p}-d_{p n}-d_{p d}-d_{p z}-d_{p v}$ & $\frac{d P}{d t}=d_{n p}-d_{p n}-d_{p d}-d_{p z_{1}}-d_{p v_{1}}$ \\
\hline $\mathbf{Z}$ & $\frac{d Z}{d t}=d_{p z}-d_{z d}-d_{z n}$ & $\frac{d Z}{d t}=d_{p z}-d_{z d}-d_{z n}$ & $\frac{d Z_{x}}{d t}=d_{p z_{x}}-d_{z_{x} d}-d_{z_{x} n}(x=1$ and 2$)$ \\
\hline $\mathbf{N}$ & $\frac{d N}{d t}=d_{p n}+d_{d n}+d_{z n}-d_{n p}$ & $\frac{d N}{d t}=d_{p n}+d_{d n}+d_{z n}-d_{n p}$ & $\frac{d N}{d t}=d_{b n}+d_{p n}+d_{z_{1} n}+d_{z_{2} n}-d_{n p}$ \\
\hline D & $\frac{d D}{d t}=d_{p d}+d_{z d}-d_{d n}$ & $\frac{d D}{d t}=d_{p d}+d_{z d}+\left(1-\mu_{v}\right) V+d_{v d}-d_{d n}$ & $\frac{d D}{d t}=d_{p d}+d_{z_{1} d}+d_{z_{2} d}+\left(1-\mu_{v}\right) V+d_{v_{1} d}+d_{v_{2} d}-d_{d b}$ \\
\hline B & - & - & $\frac{d B}{d t}=d_{d b}-d_{b n}-d_{b z_{2}}-d_{b v_{2}}$ \\
\hline $\mathbf{V}$ & - & $\frac{d V}{d t}=d_{p v}-d_{v d}$ & $\frac{d V_{x}}{d t}=d_{p v_{x}}-d_{v_{x} d}(\mathrm{x}=1$ and 2$)$ \\
\hline
\end{tabular}

Note: the parameter values for the $\mathrm{d}$ terms are: the maximum grazing rate on phytoplankton $\left(\boldsymbol{p}_{\max }\right) 0.2 \mathrm{~d}^{-1}$; the zooplankton excretion rate $\left(\boldsymbol{r}_{\mathrm{zn}}\right) 0.01 \mathrm{~d}^{-113]}$; the zooplankton mortality rate $\left(\boldsymbol{m}_{\mathrm{z}}\right) 0.02 \mathrm{~d}^{-111}$; the maximum phytoplankton nutrient uptake rate $\left(\boldsymbol{r}_{\max }\right) 1.0 \mathrm{~d}^{-1[1,2,4]}$; the minimum photosynthetically active radiation $\left(\boldsymbol{I}_{\min }\right) 25 \mathrm{~W} / \mathrm{m}^{2[3]}$; the phytoplankton mortality rate $\left(\boldsymbol{m}_{\mathrm{p}}\right) 0.02 \mathrm{~d}^{-1[3]}$; the phytoplankton viral production rate $\left(\boldsymbol{\mu}_{\mathbf{v}}\right)$ $0.16 \mathrm{~d}^{-1[5]}$; the bacterial viral production rate $\left(\boldsymbol{\mu}_{\mathrm{vB}}\right) 0.1 \mathrm{~d}^{-1}$; the phytoplankton viral decay rate $\left(\mathbf{r}_{\mathrm{vd}}\right) 1.23 \mathrm{~d}^{-1[5]}$; the bacterial viral decay rate $\left(\mathbf{r}_{\mathrm{vdB}}\right) 0.05 \mathrm{~d}^{-1[6]}$; the phytoplankton excretion rate $\left(\boldsymbol{r}_{\mathrm{pn}}\right) 0.01 \mathrm{~d}^{-1[3]}$; the

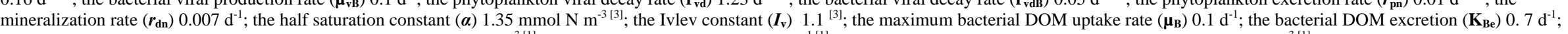
the half saturation constant for bacteria function $\left(\mathbf{K}_{\mathbf{B}}\right) 0.97 \mathrm{mmolN} \mathrm{m}^{-3[1]}$; the grazing rate on bacteria $\left(\mathbf{g}_{\mathbf{r}}\right) 9 \mathrm{~d}^{-1[1]}$; the half saturation constant for grazing $\left(\mathbf{K z}^{2}\right) 145.8 \mathrm{mmolN} \mathrm{m}^{-3[1]}$

[1] Gal et al. (2009); [2] Van den Meersche et al. (2004); [3] Burchard et al. (2005); [4] Pollingher and Berman (1982); [5] Rhodes and Martin (2010); [6] Heldal and Bratbak (1991). 


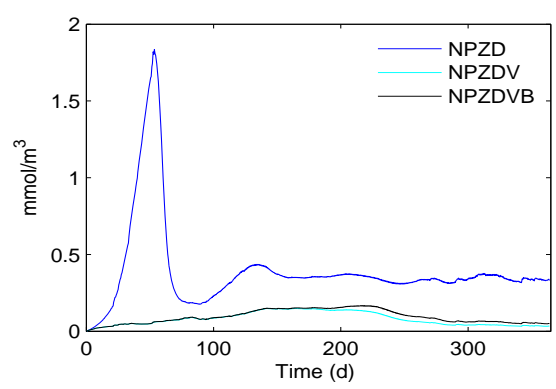

(a) phytoplankton

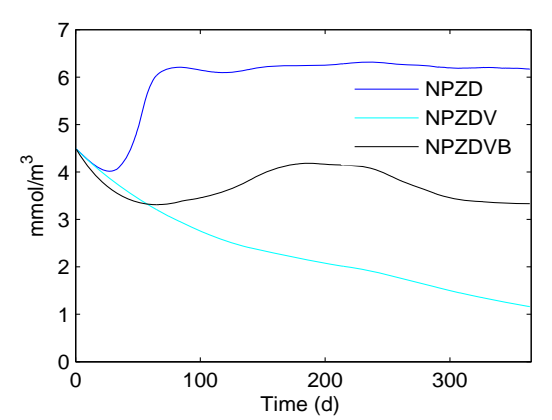

(c) detritus

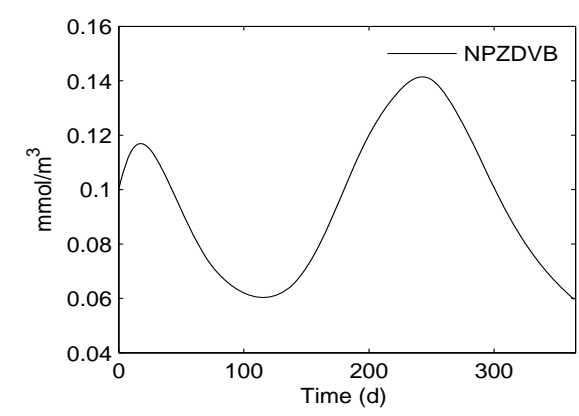

(e) bacteria

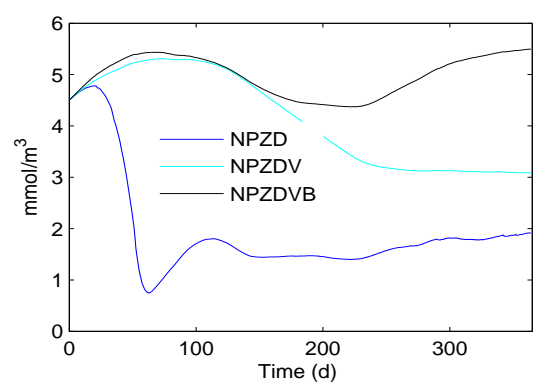

(b) nutrient

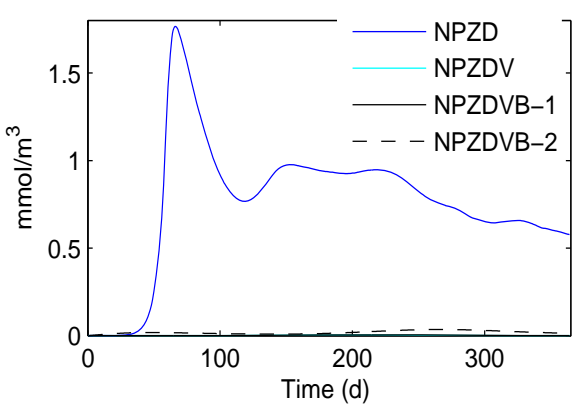

(d) zooplankton

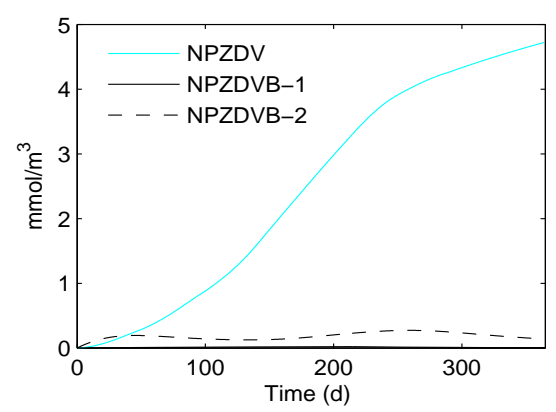

(f) viruses

Figure 2. Simulated biological compartments with three ecological models.

Table 2. Summary of simulated nutrient fluxes $\left(\mathrm{mmol} / \mathrm{m}^{3} \mathrm{~d}^{-1}\right)$ for the three ecological models.

\begin{tabular}{lccc}
\hline Pathway & NPZD & NPZD+V & NPZD+VB \\
\hline Phytoplankton uptake & $0.0448(100)$ & $0.0148(100)$ & $0.0174(100)$ \\
Phytoplankton excretion & $0.0039(9)$ & $8.1 \mathrm{e}-04(6)$ & $9.4 \mathrm{e}-04(5)$ \\
Phytoplankton mortality & $0.0079(18)$ & $0.0016(11)$ & $0.0019(11)$ \\
Zooplankton grazing & $0.0243(54)$ & $5.1 \mathrm{e}-05(0.3)$ & $6.6 \mathrm{e}-05(0.4)$ \\
Microzooplankton grazing & - & - & $6.1 \mathrm{e}-04(3.5)$ \\
Zooplankton excretion & $0.0076(17)$ & $1.7 \mathrm{e}-05(0.1)$ & $2.1 \mathrm{e}-04(1.2)$ \\
Zooplankton mortality & $0.0151(34)$ & $3.3 \mathrm{e}-05(0.2)$ & $4.2 \mathrm{e}-04(2.4)$ \\
Mineralization & $0.0355(79)$ & $0.0140(95)$ & - \\
Viral production (phytoplankton) & - & $1.5 \mathrm{e}-07(0.1)$ & $0.0151(87)$ \\
Viral production (bacteria) & - & - & $0.0096(55)$ \\
Viral decay & - & $3.5 \mathrm{e}-05(0.2)$ & $0.0243(140)$ \\
Bacterial uptake & - & - & $0.0335(193)$ \\
Bacterial excretion & - & - & $0.0235(135)$ \\
\hline
\end{tabular}

Note: values in () are provided as \% of total nutrient taken up by phytoplankton. 


\section{DISCUSSION}

The increase in model complexity from the NPZD model to the NPZD+VB model indicates that microbial interactions (the microbial loop and the viral shunt) are an important determinant of algal biomass. The serial NPZD model, the NPZD+V model, and the NPZD+VB model generated markedly different results, especially for the phytoplankton compartment.

In the OD FABM platform, the present simulations are mostly steady with only seasonally varying changes in light and temperature. This would be valid for real ecosystems with similar physical conditions as Lake Kinneret. However, the effect of hydrodynamics, such as inflow events and mixing, would change the seasonality of the majority of chemical and biological variables. This also would change the simulated magnitude of algal blooms in aquatic ecosystems (e.g., see Keller and Hood, 2011). These limitations of the different models indicate that under more physically realistic conditions the effect of microbial interactions will of course manifest differently in a real aquatic ecosystem and these simulations are intended to help us gain insights into system dynamics.

Scientists need to make an appropriate choice of model complexity depending on the type of aquatic ecosystems. The three compartment NPZ model or the four compartment NPZD model have been applied and coupled to hydrodynamic models for exploring physical-chemical-biological interactions in aquatic ecosystems (Edwards, 2001; Frank, 2002). For example, the classic NPZ model has been successful for studying spring algal blooms in North Pacific Sea (McGillicuddy et al., 1995). However, these models must be used carefully and appropriately after checking if the ecosystem is dominated by simple interactions between phytoplankton and zooplankton. When the microbial community has high virus numbers, such as in some lakes (Laybourn-Parry et al., 2001; Madan et al., 2005), the NPZD+V model or the NPZD+VB model can better capture the pivotal role of viruses in $\mathrm{C}$ and nutrient recycling. When bacteria and virus parameters and validation data are not available for modelling the viral shunt and the microbial loop in some aquatic ecosystems, scientists need to constrain their parameters with literature review data in these models to test their scientific hypothesis with the improved NPZD+V, or NPZD+VB modelling framework. For example, to get the same phytoplankton biomass in the NPZD+VB model as in the NPZD model, the photosynthesis rate need to be increased by around $50-100 \%$ to get the phytoplankton biomass in NPZD+VB to match in NPZD in the future. If an ecological model misses an important microbial structural component (e.g. the viral shunt), some of the inappropriate model structure will ultimately be expressed in the parameter variability and uncertainty. This is likely a common occurrence and erroneous parameters are readily transferred between different modelling studies of aquatic ecosystems. Further understanding of the sensitivity of the various parameters and model algorithms is also required.

The model structures presented here each have a unique state-space relationship (not shown) for a comparable parameter set, and thus it is likely they will respond to perturbation differently in each case. Heinle and Slawig (2013) demonstrated that even subtle assumptions about NPZD model parameterisation can cause changes in system stability and dynamics, and further work is required to ascertain the relative resilience of these different model structures. Given many modeling studies are motivated to assess whether aquatic ecosystems will respond to nutrient loading or climate change (Mooij et al., 2010), an understanding of how model assumptions impact on their predictions of regime shifts and stable states is a necessary area of further research.

Based on the mathematical basis and the relatively simplistic parameterisation for developing the models here, further plans exist to apply ecological stoichiometry principles to these models to provide dynamic scenarios of microbial interactions with appropriate field datasets. In this way, it is intended to also define quantitatively how these microbial interactions influence stoichiometric controls on phytoplankton growth in aquatic ecosystems (Li, 2013). Overall, the ultimate aim of understanding these alternative ecological models is to highlight the importance of the microbial loop on the development of algal blooms and of the viral shunt on terminating algal blooms. This understanding helps us understand the important driving variables controlling algal population dynamics, and can ultimately help us manage algal blooms in human-dominated environments.

\section{REFERENCES}

Anderson, D. M., Glibert, P. M. \& Burkholder, J. M. (2002) Harmful algal blooms and eutrophication: Nutrient sources, composition, and consequences. Estuaries, 25, 704-726.

Burchard, H., Deleersnijder, E. \& Meister, A. (2005) Application of modified Patankar schemes to stiff biogeochemical models for the water column. Ocean Dynamics, 55, 326-337. 
Edwards, A. M. (2001) Adding detritus to a Nutrient-Phytoplankton-Zooplankton model: A dynamicalsystems approach. Journal of Plankton Research, 23, 389-413.

Franks, P. J.S. (2002) NPZ models of plankton dynamics: Their construction, coupling to physics, and application. Journal of Oceanography, 58, 379-387.

Gal, G., Hipsey, M.R., Parparov, A., Wagner, U., Makler, V., \& Zohary, T. (2009) Implementation of ecological modeling as an effective management and investigation tool: Lake Kinneret as a case study. Ecological Modelling, 220, 1697-1718.

Gobler, C.J., Hutchins, D.A., Fisher, N.S., Cosper, E.M. \& Sanudo-Wilhelmy, S.A. (1997) Release and bioavailability of $\mathrm{C}, \mathrm{N}, \mathrm{P}$, Se and Fe following viral lysis of a marine chrysophyte. Limnology and Oceanography, 42, 1492-1504.

Guven, B. \& Howard, A. (2006) A review and classification of the existing models of cyanobacteria. Progress in Physical Geography, 30, 1-24.

Hambright, K. D., Zohary T. \& Gude, H. (2007) Microzooplankton dominate carbon flow and nutrient cycling in a warm subtropical freshwater lake. Limnology and Oceanography, 52, 1018-1025.

Heldal, M. \& Bratbak, G. (1991) Production and decay of viruses in aquatic environments. Marine Ecology Progress Series, 72, 205-212.

Heinle, A. \& Slawig, T. (2013) Internal dynamics of NPZD type ecosystem models. Ecological Modelling, 254, 33-42.

Keller, D. P. \& Hood, R. R. (2011) Modeling the seasonal autochthonous sources of dissolved organic carbon and nitrogen in the upper Chesapeake Bay. Ecological Modelling, 222, 1139-1162.

Laybourn-Parry, J., Höfer, J. \& Sommaruga, R. (2001) Viruses in Antarctic freshwater and saline lakes. Freshwater Biology, 46, 1279-1287.

Li, Y. (2013). Unravelling microbial interactions in aquatic ecosystems: an improved model of microbial controls on nutrient processing. PhD thesis, University of Western Australia.

Li, Y., Waite, A., Gal, G. \& Hipsey, M. (2013) An analysis of the relationship between phytoplankton internal stoichiometry and water column N:P ratios in a dynamic lake environment. Ecological Modelling, 252,196-213.

Madan, N. J., Marshall, W.A. \& Laybourn-Parry, J. Virus and microbial loop dynamics over an annual cycle in three contrasting Antarctic lakes. Freshwater Biology, 50, 1291-1300.

McGillicuddy, D.J., Robinson A.R. \& McCarthy, J.J. (1995) Coupled physical and biological modelling of the spring bloom in the North-Atlantic.1.3-dimensional bloom and post-bloom processes. Deep-Sea Reserach I, 42, 1359-1398.

Moore, J.C., Berlow, E.L., Coleman, D.C., Ruiter, P.C., Dong, Q., Hastings, A., Johnson, N.C., McCann, K.S., Melville, K., Morin, P.J., Nadelhoffer, K., Rosemond, A.D., Post, D.M., Sabo, J.L., Scow, K.M., Vanni, M.J. \& Wall, D.H. (2004). Detritus, trophic dynamics and biodiversity. Ecological Letters, 7, 584600.

Pollingher, U. \& Berman, T. (1982) Relative contributions of net and nano-phytoplankton to primary production in Lake Kinneret. Archiv fur Hydrobiologie, 96, 33-46.

Pomeroy, L.R., Leb, P.J., Azam, W.F.\& Hobbie, J.E. (2007) The Microbial Loop. Oceanography, 20, 28-33.

Popova, E.E., Ryabchenko, V.A. \& Fasham, M.J.R. (2000) Biological pump and vertical mixing in the southern ocean: their impact on atmospheric $\mathrm{CO}_{2}$. Global Biogeochemical Cycles, 14, 477-498.

Rhodes, C.J. \& Martin, A.P. (2010) The influence of viral infection on a plankton ecosystem under going nutrient enrichment. Journal of Theoretical Biology, 265, 225-237.

Suttle, C. A. (2005) Viruses in the sea. Nature, 437,356-361.

Vanden Meersche, K., Middelburg, J. J., Soetaert, K., van Rijswijk, P., Boschker, H.T.S. \& Heip, C.H.R. (2004). Carbon-nitrogen coupling and algal-bacterial interactions during an experimental bloom: modeling a 13C tracer experiment. Limnology and Oceanography, 49, 862-878.

Wilhelm, S.W. \& Suttle, C.A. (1999) Viruses and nutrient cycles in the sea. BioScience, 49, 781-788.

Wommack, K.E. \& Colwell R.R. (2000) Virioplankton: viruses in aquatic ecosystems. Microbiology and Molecular Biology Reviews, 64, 69-114. 